Article

\title{
Are Non-R\&D Innovation Activities Actually Effective for Innovation Sustainability? Empirical Study from Chinese High-Tech Industry
}

\author{
Jian Hou *(D), Jiancheng Chen *, Hongfeng Song and Gang Wang \\ School of Economics and Management, Beijing Forestry University, Beijing 100083, China; \\ songhf@bjfu.edu.cn (H.S.); wanggang@bjfu.edu.cn (G.W.) \\ * Correspondence: houjian1128@bjfu.edu.cn (J.H.); chenjc1963@163.com (J.C.); Tel.: +86-137-0128-3351 (J.H.); \\ +86-10-6233-8111 (J.C.)
}

Received: 7 December 2018; Accepted: 23 December 2018; Published: 31 December 2018

\begin{abstract}
Compared with developed countries, the paper explores whether non-R\&D innovation activities in China actually are effective and provides a guidance on how we can choose a sustainable innovation mode for non-R\&D, especially considering the "threshold effect" of the heterogeneity of different regional innovation levels. The dynamic threshold panel models of the non-R\&D (NRD) effect on the basis of the threshold of regional innovation level is constructed to verify the complex "threshold effect" characteristics between non-R\&D and innovation performance. The empirical results are discussed according to the panel data for 30 provinces in China concerning the high-tech industry. Results argue that the mechanism of non-R\&D innovation activities on innovation performance have a significantly different "threshold effect." Interestingly, when the threshold of regional innovation keeps a low level, the negative effect of non-R\&D innovation activities is much larger. When the threshold level of regional innovation increases, reaching the critical mass, the negative impact of non-R\&D innovation activities on innovation performance becomes smaller. However, once the regional innovation level crosses the critical mass, the negative impact of non-R\&D shows a significantly increasing tendency. Specifically, neither much higher nor much lower regional innovation level is conducive to the promoting effect of non-R\&D activities. The negative impact of non-R\&D on performance will decrease to the minimum only in the regions within the moderate threshold level (critical mass). The dynamic nonlinear mechanism between non-R\&D activities and innovation performance is empirically studied to assist high-tech enterprises for innovation sustainability based on heterogeneity of different regional innovation levels.
\end{abstract}

Keywords: non-R\&D innovation activities; innovation sustainability; regional innovation level; dynamic threshold effect; high-tech industry; China

\section{Introduction}

Innovation sustainability has enabled enterprises to perform better in the social and environmental dimensions while enhancing their financial performance [1,2]. Boons and Lüdeke-Freund [3] pointed out the integration of environmental and social activities, as well as the internalization of socio-environmental costs and the fundamental role played by innovation can effectively create a truly sustainable value. Innovation sustainability is the driving force and the fundamental path for development of social and ecological sustainability. Nowadays, environmental pollution and energy consumption have brought severe challenges to the global ecosystem and social and economic development. In view of the global ecological sustainability, it is essential for the industry sector to choose the path of sustainable innovation and take the lead in realizing 
the transformation from extensive economic growth to innovation sustainability in the context of addressing sustainable development targets. This leadership would have a profound demonstration effect on promoting the development of ecology and economic sustainability around the world. Specifically, the economic downturn and fierce competition have motivated enterprises to focus on innovation, and the sustainable innovation mode shows an increasingly diversified tend, as have the identified sources of innovation [4]. In the changing context of innovation practices, scholars have extensively studied and discussed the concept of open innovation [5]: In the process of innovation, access to innovative resources and improvements in innovation performance can be achieved not only through internal channels but also through outside channels; that is, the boundary between the firm and the external innovation environment has weakened. Innovation is no longer equivalent to R\&D, and there are many other types of non-R\&D innovation activities [6].

During the transformation of innovation sustainability from internal $R \& D$ to diversified opening innovation, due to the lack of necessary innovation resources in developing countries, the technology transfer or non-R\&D innovation activities (i.e., the acquisition of foreign technology) are considered the primary source of technological innovation [7]. Generally, developing countries mainly focus on activities in the middle and low end of the global innovation chain, and there is a larger window of opportunity for their technology sustainability through the use of new innovation modes. On the one hand, $R \& D$ is the main force to promote regional sustainable innovation development [8-11]. Normally, R\&D activities play a key role in technological innovation of enterprises, which are the core source of sustainable innovation-driven development. In the process of sustainable innovation, the scale and intensity of R\&D expenditure largely reflect the sustainability of enterprise innovation in the traditional closed innovation [10,11]. However, given the knowledge diffusion among regions, the technology life cycle is shortening, and the risk of relying solely on R\&D has increased. Profound changes have occurred in the allocation of regional innovation sustainability, and the virtuous cycle has gradually broken. Especially for developing countries, the resources needed for sustainable innovation become more dispersed. It is becoming more and more difficult to sustainable R\&D in frontier areas. Therefore, in order to sustainability, the traditional R\&D model of most developing countries is increasingly changing to "open innovation," emphasizing seeking more innovative activities besides $R \& D$, i.e., non-R\&D innovation activities. Practice shows that non-R\&D innovation is not only a sustainable way of innovation, but also a sustainable transformation strategy for innovation in developing countries [6,12]. Non-R\&D innovation can compensate for the lack of innovation resources and R\&D capabilities of enterprises, expand the access to technological knowledge, and cope with the increasing cost risks and technological complexity of innovation. Non-R\&D innovation is even better than R\&D innovation under some conditions, which has a significant impact on innovation sustainability of enterprises.

China has recently narrowed its gap in technical level by unprecedented technology introduction and external cooperation with developed countries. Nevertheless, this non-R\&D mode has had serious path dependence effects, leading to an awkward situation for Chinese enterprises stemming from the shortage of independent property rights. Meanwhile, like other developing countries, China's allocation of innovation resources is very uneven, and most of the foundation for high-tech industry's R\&D is relatively weak because of resource constraints [13]. Thus, the implementation of non-R\&D innovation activities occurs under poor foundational conditions, and the structure is fragmented, with no scale or regularity. As a result, the corresponding driving mechanisms may be limited. It is thus necessary to conduct localized research under the current period of transformation in China's innovation sustainability and to further explore rational and effective diversified innovation strategies. This situation prompts the following questions: Compared with developed countries, how can we choose a sustainable innovation mode for non-R\&D, especially considering the unique background of China's weak innovation foundation and major differences in regional innovation levels? Are non-R\&D innovation activities in China actually effective for innovation sustainability? 
The rest of this paper is structured as follows. Section 2 provides an overview of the related literature. Section 3 presents the methodology and empirical specifications. Section 4 describes the estimation variables and our database. Section 5 discusses the empirical results. Section 6 closes the paper with some conclusions.

\section{Literature Review}

Relevant academic studies and innovation policies mostly focus on the promotion of R\&D capabilities. In contrast, the role of non-R\&D activities has been ignored for a long time, i.e., research by Arundel et al. [12] shows that in terms of the distribution of European business innovation support funds, approximately $95 \%$ are used for R\&D, whereas only 5\% support non-R\&D innovation activities. Brouwer and Kleinknecht [14] researched the related expenditure of non-R\&D activities in product innovation. Sterlacchini [15] also offers early discussions of non-R\&D activities in enterprises. At this stage, however, scholars have only proposed some of the activities that do not rely on R\&D: The concept of non-R\&D innovation activities has not been formally proposed. For the concept of non-R\&D activities, many studies have considered non-R\&D activities mainly including investment, product design, patents, human labors and external resources [6]. Subsequently, the Organization for Economic Cooperation and Development (OECD) [16] stated the fundamental principles between R\&D and non-R\&D activities. Specifically, for developing countries, non-R\&D innovation activities includes innovation-related activities that do not involve R\&D-related activities [17]. From the input perspective, non-R\&D activities can be regarded as multi innovation modes not related to R\&D activities [18].

Regarding the development and subdivision modes of non-R\&D, in the early 1990s, the OECD and the EU, in particular through the Community Innovation Survey (CIS), have started to count not only $R \& D$ expenses but also innovation expenses that are not $R \& D$ and these statistical efforts have shown that non-R\&D activities are quite large and explain innovation output of non-R\&D [19,20]. In the 2000s, a more systematic analysis came into fruition based on the results of CIS and the Oslo Manual. Evangelista et al. [21] divided innovation activities into R\&D activities, non-R\&D activities and investment activities, showing that the proportion of non-R\&D innovation activities is higher in some Small and Medium Enterprises (SMEs). Evangelista and Mastrostefano [22] argue that the purchase of new machines, equipment and technology is the most obvious non-R\&D activity, or one of the main innovation modes [23]. Technology adoption is used as an important mode of non-R\&D activity to provide more direct technical resources, reduce production costs, improve technical capabilities, and promote enterprise performance [24]. Kim and Nelson [25] believe that imitation innovation in enterprises does not require high technology capabilities, and therefore is often not based on R\&D. Indeed, a great deal of existing knowledge in the enterprise is often not well utilized, and the cost of creating new knowledge is often higher than that of the existing knowledge. It is also a mode of non-R\&D to integrate the existing knowledge of enterprises [21]. Heidenreich [26] found that the main characteristics of the low-tech industry are process, organizational and marketing innovation, upon which the non-R\&D activities of SMEs - such as external machinery, equipment and software-are strongly dependent. Organizational innovation, market innovation, design and service innovation play the significant role in innovation for the SMEs of low- and medium-tech industries [27]. In recent years, the representative studies are Arundel et al. [12] and Som [28], who research the different relationships and characteristics of R\&D and non-R\&D innovation activities, respectively. Arundel et al. [12] offered the first systematic study of non-R\&D activities. They summarize four typical patterns of activities from the literature: Technology introduction, gradual improvement, reverse imitation and existing knowledge combination. They conclude that there is no obvious difference in economic benefits between internal $R \& D$ enterprises and non-R\&D enterprises from the perspective of profit growth. Moreover, Som [28] summarizes five types of non-R\&D enterprises in German: Knowledge-intensive developers; customer-driven experts; temporary B2C product developers; low-innovation, labor-intensive manufacturing; and the flexible production of specialized suppliers. 
Furthermore, there are a few major studies on the relationship between non-R\&D innovation activities and innovation performance in European countries [29]. As there are no formal R\&D institutions, non-R\&D activities are very frequent in SMEs [15,30], whose innovation performance is positively affected. Santamaría et al. [6] analyzes the influence of discrepant non-R\&D innovation activities and different sources of innovation on enterprise innovation output based on data for Spain's low-tech and high-tech manufacturing industries and find that non-R\&D innovation activities show a significant influence on the innovation of all types of enterprises. Hervas-Oliver et al. [31] reaches similar conclusions. In particular, non-R\&D innovation activities lead to innovation activities like technology forecasting, designing, the advanced manufacturing technologies employment and training. In addition, non-R\&D technological innovators heavily use organizational and marketing activities to compensate for their lack of engagement in R\&D innovation activities [32]. In some cases, there exists a complementary relationship between R\&D activities and non-R\&D activities: Non-R\&D mode plays a complementary role in R\&D [33]. In general, non-R\&D innovation activities are a crucial factor in the product and process innovation of any enterprise, especially when the enterprise has not conducted R\&D management. The construction of innovation can be formed by different working practices and different processes, not just by R\&D labs [34]. Compared with developed countries, where low- and medium-tech industries or SMEs are generally related to non-R\&D activities, there are differences in innovation practice in developing countries, technical resources are very limited and technological innovation capacity is low, even in the high-tech industry, with R\&D intensity showing a large gap from the average level of developed countries. For instance, there are many non-R\&D innovation activities in the high-tech industry of China [35]. In China, Chen and Chen [36] argued that innovation investments mainly included technology introduction, digestion, absorption and transformation and other non-R\&D expenses, revealing the indispensable role played in the sustainable development of the regional innovation environment. Guan and Chen [37] thought that the technology innovation performance is due to the intertwined endeavors of R\&D and non-R\&D innovation inputs by using an empirical study. There exists the promotion and substitution effect of non-R\&D activities on innovation performance for Chinese high-tech industry [35].

In summary, the current research on the non-R\&D innovation mode is still relatively scarce for developing countries. Most studies have confirmed that non-R\&D activities showing positive effects on innovation performance in developed countries, but there are no many in-depth studies on the sustainable mechanism through which non-R\&D innovation activities have an impact on developing countries. In particular, the influence of innovation level on the effects of non-R\&D activities in China has been overlooked. Differences in innovation environments with different thresholds of regional innovation level may have different nonlinear effects on $R \& D$ and non- $R \& D$ modes. Consequently, non-R\&D innovation activities are not necessarily just a positive effect or linear relation in China. In order to highlight these research gaps and further enrich the theory of non-R\&D, compared with developed countries, we consider the innovation characteristics (thresholds) of most developing countries. Based on the improved dynamic threshold panel model, we explicitly analyze whether non-R\&D innovation activities are effective and explore the nonlinear impact mechanism of non-R\&D under different innovation thresholds. We thus construct a sustainable evidence of the diversified innovation sustainability modes to apply to developing countries.

\section{Methodology and Model}

According to the theoretical mechanism of non-R\&D modes, we note that with China's weak innovation foundation and uneven allocation of innovation resources, the innovation mode clearly has its own characteristics. Any employed innovation mode must cater to the specific technical level: Ignoring the key factor of regional innovation level in China's situation will cause a biased estimation. Therefore, the threshold effect of the innovation mode may exist [4]. To examine whether there is a significant nonlinear relationship, the panel threshold regression model study is firstly 
proposed by Hansen [38]. These mathematical studies are most widely used in previous publications. However, most of them focus on static panel model and ignore the dynamic characteristics and the lag effect of sample objects, also neglect the endogenous variable consideration (the model's endogeneity).

Accordingly, this paper studies the lag-effect by introducing lag variables and highlights the dynamic factors by using a dynamic panel method proposed by Blundell and Bond [39]. Then, according to the process of dynamic panel estimation method, we first estimated the dynamic panel threshold. Secondly, the effect coefficients and differences between threshold intervals were explored based on 'System-GMM' [39]. Thus, we incorporated the innovation level into the dynamic influence mechanism of non-R\&D modes under the heterogeneity of the innovation threshold in China and to determine how to optimize innovation activities based on these thresholds.

Next, based on related findings of innovation [40-44], in addition to non-R\&D innovation activities, we have also chosen factors like R\&D human capital, R\&D innovation, and foreign trade as control variables. It should be noted that to consider the time-lag effect of the input variables in the entire process from input of innovation resource into the final output [45], we set the time-lag for one year according to China's actual production experience [46]. In other words, we used the $t-1$ period of $I R D, N R D, R D H$ variables relating to the source of investment as input of the $t$ period of innovation output $Y$.

Finally, adding the difference features of the regional innovation level, we constructed a single threshold panel model of the non-R\&D (NRD) effect based on the threshold of regional innovation level:

$$
\begin{gathered}
Y_{i t}=\theta+\alpha_{1} Y_{i t-1}+\alpha_{2} Y_{i t-2}+\alpha_{3} R D H_{i t-1}+\alpha_{4} I R D_{i t-1}+\alpha_{5} E X P_{i t}+\beta_{1} N R D_{i t-1} I\left(P A T_{i t} \leq \gamma\right) \\
+\beta_{2} N R D_{i t-1} I\left(P A T_{i t}>\gamma\right)+\mu_{i}+v_{t}+\varepsilon_{i t}
\end{gathered}
$$

In the above formula, $i$ and $t$ represent province and year, respectively; $Y$ is innovation performance; $R D H$ is R\&D human capital; IRD is internal R\&D innovation activities; EXP is foreign trade (export ratio); $N R D$ is non-R\&D innovation activities; $P A T$ is the threshold variable (here, the regional innovation level); $\mu$ denotes the individual effect; $\gamma$ denotes threshold variable value; $v$ denotes time effect; and $\varepsilon$ is a random disturbance variable.

The following is the multi-threshold panel model of non-R\&D (NRD) (with a double threshold as an example):

$$
\begin{gathered}
Y_{i t}=\theta+\alpha_{1} Y_{i t-1}+\alpha_{2} Y_{i t-2}+\alpha_{3} R D H_{i t-1}+\alpha_{4} I R D_{i t-1}+\alpha_{5} E X P_{i t}+\beta_{1} N R D_{i t-1} I\left(P A T_{i t} \leq \gamma_{1}\right) \\
+\beta_{2} N R D_{i t-1} I\left(\gamma_{1}<P A T_{i t} \leq \gamma_{2}\right)+\beta_{3} N R D_{i t-1} I\left(P A T_{i t}>\gamma_{2}\right)+\mu_{i}+v_{t}+\varepsilon_{i t}
\end{gathered}
$$

where $\gamma_{1}$ and $\gamma_{2}$ are the double threshold values.

\section{Variables and Data Collection}

\subsection{Measurement of Variables}

\subsubsection{Dependent Variable}

Innovation performance $(\mathrm{Y})$. The ultimate outcome of innovation sustainability is improved product sales. Innovative sustainable output primarily occurs through the sale of new products or technology bringing revenue to the enterprise, which reflects innovation sustainability in the application value and the level of commercialization [44]. Therefore, we measured sustainable innovation performance using "the ratio of new product sales revenue to revenue from the principal business" [47,48].

\subsubsection{Independent Variables}

Non-R\&D innovation activities (NRD). Our examination focuses on the effect of non-R\&D innovation activities, trends and differences according to the practical characteristics of the high-tech 
industry in China. From the perspective of innovation input, we employed various "expenditures on non-R\&D innovation activities" as a proxy indicator, mainly including expenses on the following items: Foreign technology acquisition, technology assimilation, domestic technology purchasing, and technical renovation $[12,35,41,49]$. As input variables, we also adopted a lag phase form and calculated the capital stock.

\subsubsection{Threshold Variable}

Regional innovation level (PAT). A threshold means that innovation path selection needs to be consistent with the innovation development level [50]. The regional innovation level determines the innovation sustainability of the different region, and reflects the regional innovation status and development potential of innovation. As the direct output of scientific and technological achievements in R\&D activities, patents have long been used as a well-established proxy for measuring regional innovation level [51-53]. Patent applications represent the actual strength of $R \& D$ in various regions. Patent applications for inventions have high technical content and are rarely subject to restrictions in the ability to review by the patent licensing authority. Inventions can more objectively reflect the original innovation capability of the high-tech industry and the comprehensive strength of science and technology. Thus, we adopted the number of patents for inventions in the high-tech industry as a measure of the regional innovation level and its differences.

\subsubsection{Control Variables}

$R \& D$ innovation activities (IRD). R\&D innovation activity plays a significant role in the development of enterprise technological innovation, and it is the main source of innovation for enterprises, industries and even countries. During the process of technological innovation activities, R\&D input is essential. Its scale and intensity are a major index to measure the innovation capability of enterprises, and also it is one of the main ways to form the core competitiveness of an enterprise $[10,11]$. Based on the accounting system of R\&D activities in Chinese enterprises, empirically, we used expenditures on basic research, applied research and experimental development as a proxy index to quantitatively measure the extent of $R \& D$ innovation activity $[37,48]$. Furthermore, considering the practical situation of the high-tech industry in China, we adopted a lag phase for the variable and calculate R\&D stock.

R\&D human capital $(R D H)$. For the high-tech industry, the quality of labor can reflect the absorption of new knowledge and the development of new technology. As a crucial ingredient of the knowledge function, R\&D human capital provides the basis and potential for enterprises to conduct technical innovation, which affects their innovation ability [54]. In this paper, the "full-time R\&D personnel" was used to measure R\&D human capital.

Export ratio $(E X P)$. Recently, many publications have regarded exports as a significant indictor to knowledge transfer promotion. Under the current open economy circumstance, China has paid much more attention to the situation of import and export trade. In addition, under the background of intellectual property protection internationalization and the tendency of "Intellectual property barriers" and "patent pirates", Export ratio has become a crucial factor in promoting innovation development, which reflects the convergence degree between high-tech industry and international standards [41,44]. The ratio of the export delivery value was employed to be a proxy indicator in our paper [41].

\subsection{Description of the Data}

The dataset used in this research is provincial panel data (considering the practical situation of data shortage, we exclude the Special Administrative Regions of Tibet, Hong Kong and Macau) of high-tech industries from 2005 to 2014 in China. The original data were primarily taken from the National Bureau of Statistics of China. It should be noted that to eliminate the effect of price changes, traditional expenditure on $R \& D$ was processed with a "price deflator for $R \& D$ (the weighted average of the consumer price deflator and the fixed-asset investment price deflator, with the weights estimated 
by the data in the statistical yearbook of China's high technology industry, which is 0.55 and 0.45 , respectively)." The various expenses on non-R\&D innovation activities with the same-period GDP deflator and the total output value with corresponding industrial producer price deflators all take 2005 as the base period. Collected data were processed by using Stata 13.0. (StataCorp LLC, TX, USA). Table 1 summarizes the descriptive statistics of variables.

Table 1. The descriptive statistics for each variable.

\begin{tabular}{cccccc}
\hline Variable & Mean & Median & Variance & Minimum & Maximum \\
\hline $\mathrm{Y}$ & 0.20 & 0.17 & 0.02 & 0.00 & 0.62 \\
PAT & 5.40 & 5.52 & 4.35 & 0.00 & 10.45 \\
$I R D$ & 12.42 & 12.69 & 4.60 & 5.29 & 16.95 \\
NRD & 13.00 & 12.84 & 1.14 & 10.55 & 15.37 \\
RDH & 8.24 & 8.67 & 3.66 & 1.61 & 12.32 \\
EXP & 0.29 & 0.18 & 0.11 & 0.00 & 2.50 \\
\hline
\end{tabular}

\section{Empirical Results and Discussion}

In our subsequent analyses, we examine how non-R\&D innovation activities stimulate innovation performance under different innovation thresholds based on Hansen's threshold model (1999) [38].

\subsection{Threshold Significance Test and Confidence Interval}

First, the threshold significance test and confidence intervals using the regional innovation level as the threshold variable are shown in Tables 2 and 3. From the results, we know that for the driving effect of non-R\&D activities, the double threshold test and the triple threshold test both are passed at below a 5\% significance level. Accordingly, we use two thresholds of the regional innovation level as analysis case. The relationship between non-R\&D activities and innovation performance is significantly affected by the regional innovation level.

Table 2. Test results of threshold significance.

\begin{tabular}{|c|c|c|c|c|c|c|}
\hline & \multirow{2}{*}{ Model } & \multirow[b]{2}{*}{ F-Value } & \multirow[b]{2}{*}{$p$-Value } & \multicolumn{3}{|c|}{ Critical Value } \\
\hline & & & & $1 \%$ & $5 \%$ & $10 \%$ \\
\hline \multirow{3}{*}{ Non-R\&D } & Single threshold & 8.951 & 0.147 & 33.767 & 17.214 & 11.757 \\
\hline & Double threshold & $12.445^{* *}$ & 0.030 & 19.195 & 11.266 & 7.715 \\
\hline & Triple threshold & $15.955^{* *}$ & 0.030 & 25.921 & 12.671 & 8.843 \\
\hline
\end{tabular}

Table 3. Threshold estimates and confidence intervals.

\begin{tabular}{cccc}
\hline Model & Threshold Estimate & 95\% Confidence Interval \\
\hline \multirow{3}{*}{ Non-R\&D } & Single threshold & 6.483 & {$[4.812,9.208]$} \\
& Double threshold & 6.764 & {$[5.875,6.778]$} \\
& Triple threshold & 6.483 & {$[6.483,6.562]$} \\
\hline
\end{tabular}

Having tested the threshold significance, we examine the authenticity of the threshold estimate value. As the regional innovation level is the threshold variable, the double threshold values are 6.483 and 6.764 for the driving effect of R\&D innovation activities. In addition, both estimate values are located in the $95 \%$ confidence interval: 6.483 [6.483, 6.562] and 6.764 [5.875, 6.778]. The results are shown in Table 3.

It has thus been demonstrated that given the unique innovation situation and problems experienced by the developing countries mentioned in the introduction, a threshold effect from the regional innovation level exists in innovation activities. 


\subsection{Results of the Model Parameter Estimation}

Next, we consider the effect of differences in the regional innovation level and test the double-threshold models of non-R\&D (model (2)) determined from the above-mentioned analysis. The results are found in Table 4 .

Table 4. Results of the model parameter estimation.

\begin{tabular}{|c|c|c|c|c|c|c|}
\hline & Coef. & Std. Err. & $t$ & $P>|t|$ & $95 \%$ Con & Interval \\
\hline L1. & $-0.346^{* * *}$ & 0.039 & -8.79 & 0.000 & -0.428 & -0.264 \\
\hline L2. & $-0.144^{* * *}$ & 0.028 & -5.08 & 0.000 & -0.202 & -0.085 \\
\hline$R D H$ & $0.057^{* * *}$ & 0.008 & 6.99 & 0.000 & 0.040 & 0.074 \\
\hline$I R D$ & $0.060^{* *}$ & 0.027 & 2.25 & 0.035 & 0.005 & 0.115 \\
\hline EXP & $-0.102^{* * *}$ & 0.009 & -10.80 & 0.000 & -0.121 & -0.082 \\
\hline$N R D(P A T \leq 6.483)$ & $-0.829^{* * *}$ & 0.193 & -4.31 & 0.000 & -1.228 & -0.430 \\
\hline$N R D(6.483<\overline{P A} T \leq 6.764)$ & -0.191 & 0.274 & -0.70 & 0.493 & -0.758 & 0.376 \\
\hline$N R D(P A T>6.764)$ & $-0.807^{* * *}$ & 0.208 & -3.88 & 0.001 & -1.239 & -0.376 \\
\hline _cons & $0.080^{* * *}$ & 0.021 & 3.87 & 0.001 & 0.037 & 0.122 \\
\hline
\end{tabular}

For non-R\&D, the relation between non-R\&D innovation activities and innovation performance at the $1 \%$ level shows a significant negative correlation when the level of regional innovation is below 6.483 (the low innovation level), indicating that lower regional innovation abilities and levels are not conducive to non-R\&D activities stimulating innovation development in the region. When the level of regional innovation within the moderate innovation level $(6.483<P A T \leq 6.764)$, the influence coefficient of non-R\&D on innovation performance is not significant. It indicates that the negative influence of non-R\&D on innovation performance reaches the minimum value under this regional innovation level. However, when the innovation level is high $(P A T>6.764)$, the positive effect of non-R\&D on innovation performance is yet limited, showing a significant negative effect. The empirical results show the characteristics of the nonlinear threshold effect of non-R\&D.

As for the model's endogeneity and the characteristics of the dynamic changes of innovation activities, the lag variable is significant at the $1 \%$ level. Additionally, that reflects the rationality of the constructed dynamic panel threshold model. The Hansen test shows Prob $>\chi^{2}=0.971$. The test results in Table 5 also demonstrate the reasonability of the model.

Table 5. AR(1) and AR(2) test.

\begin{tabular}{lll}
\hline Order & \multicolumn{1}{c}{$\mathbf{z}$} & Prob $>\mathbf{z}$ \\
\hline $\mathrm{AR}(1)$ & -2.62 & 0.009 \\
$\mathrm{AR}(2)$ & 0.64 & 0.520 \\
\hline
\end{tabular}

\subsection{Discussion}

We find that non-R\&D innovation activities have a negative impact; this finding is not consistent with the conclusions reached when studying developed European countries. Furthermore, when the regional innovation (threshold level) is low, the negative effect of non-R\&D innovation activities becomes larger. When the regional innovation (threshold level) increases, reaching the critical mass, the negative influence of non- $R \& D$ activities on innovation performance is smaller. However, once the regional innovation level crosses the critical mass, the negative impact of non-R\&D shows a significantly increasing tendency. Concretely, neither much higher nor much lower regional innovation level is conducive to the promoting effect of non-R\&D activities. In addition, when the regional innovation reaches the moderate threshold level (critical mass $6.483<P A T \leq 6.764$ ), the negative effect of non-R\&D on innovation performance will decrease to the minimum. We believe that the innovation mode of non-R\&D in China has not played a completely positive role due to the significant limitation caused by the regional innovation. 
As a result of the weak innovation level in various regions (the threshold of the low innovation level), there is a very large gap in technology between China and developed countries, and most of the high-tech industry's R\&D foundation is weakened by resource constraints [13]. Non-R\&D innovation activities are driven by technology transfer from developed countries. China's current dependence on foreign technology (the ratio of the acquisition of foreign technology expenses to all technical expenditure) is greater than $40 \%$, whereas the United States, Japan, and other developed countries' dependence is below 30\%. China's high degree of dependence on foreign technology indicates that its rate of technological self-sufficiency is low and its ability to engage in internal $R \& D$ is weak, especially in areas of core technology. Therefore, non-R\&D innovation activities in China mostly introduce foreign technology instead of domestic technology or internal $\mathrm{R} \& \mathrm{D}$, and these technologies belong to key or core technologies that have not yet been mastered in the country. However, the development of the Chinese high-tech industry occurred relatively late; its weak innovation level and R\&D ability cannot provide the corresponding productive factors and supporting resources for the introduction of technology; and there is no systematic public mechanism for technical information, personnel training and other services. Most enterprises rely solely on foreign technologies and are not very good at digestion and absorption. Moreover, they have no ability to transform these technologies into core technology for which they have an independent property right. Consequently, China is in an awkward position of innovation, which affects its ability to engage in effective technology transfer. The gap between China and foreign countries is too large in these technologies, leading to an inability to subsequently digest and absorb innovation into domestic technology $[55,56]$.

Moreover, with the constant promotion of open innovation, the technology spillover rate continues to accelerate, the life cycle of different technology is shortening, while the risk of totally relying on $R \& D$ has increased [5]. There are many changes in the innovation resources allocation for Chinese high-tech industries, and the technology resources needed for open innovation become more dispersed and it simultaneously becomes more difficult to develop internal R\&D. Innovation in China tends to seek and mobilize external resources to make supplements on internal $R \& D$ shortage while remaining mostly confined to the single mode of acquiring foreign technology [57]. The introduction of new technology is constantly repeated and continued, and multinational enterprises are continuously accelerating the pace of technical updates. Thus, developing countries such as China will always experience a certain technical gap, being technology followers. In the mode of international vertical specialization, China will be locked into the low end of the international value chain, restricting the development path of non-R\&D. In theory, we therefore believe that the foreign technology acquisition and the technology assimilation are two main reasons for the negative non-R\&D mode, especially at the lower threshold of the innovation level.

As the domestic technology purchasing, the domestic technology level is relatively outdated (at the threshold of the low innovation level), and the technical level among enterprises is close, meaning that there is strong technology substitution and intense competition. Enterprises will take effective measures to protect their own technology instead of easily transferring technology. As a result, there is less domestic technology trading and far lower expenditures for the domestic technology purchasing than for the foreign technology acquisition. In other words, these types of non-R\&D activities play a very limited role in China. Besides, when the threshold of innovation level is relatively higher (at the threshold of the high innovation level), and with the improvement of knowledge and technology foundation in different regions, the efficiency of internal $R \& D$ increases. Enterprises could replace non-R\&D activities by choosing more internal $R \& D$. In this situation, internal $R \& D$ and non-R\&D belong to a simple alternative and can be replaced with each other. Meanwhile, technology introduction and technical renovation in non-R\&D activities will potentially reduce the need for new technology and the inherent power of technological innovation and strengthening the "inertia" of technological innovation in enterprises. Therefore, non-R\&D innovation activities served as a "replacement" for an enterprise's R\&D innovation 
efforts, and excessive reliance on non-R\&D may damage the initiative to conduct internal R\&D in China [32]. Neither much higher nor much lower regional innovation level facilities the positive impact of non-R\&D activities. Only when the regional innovation level is within the optimal interval (critical mass), the non-R\&D activities can be effectively digested, absorbed and converted into externally acquired knowledge. Through this effective translation, the externally acquired knowledge has become the real resources enterprise owned, which increases the accumulated knowledge of the organization, and decreases the cost and risk of innovation-driven implementation.

\section{Conclusions}

In this paper, we provide a new perspective for developing countries' innovation sustainability (modes) by considering the unique "threshold effect" of the heterogeneity of different regional innovation levels. We then use a panel threshold regression model to empirically test the nonlinear relationship between non-R\&D and innovation performance. The research provides interesting insights into non-R\&D innovation sustainability, enriching the relevant theoretical and empirical findings.

Inconsistent with prior studies on developed European countries, however, we find a certain negative impact of non-R\&D, which is significantly affected by the level of regional innovation. Interestingly and importantly, when the regional innovation (threshold level) is low, the negative impact of non-R\&D activities is larger. With the threshold level of regional innovation rising, reaching the critical mass, the negative effect of non-R\&D activities on innovation performance grows smaller. However, once the regional innovation level crosses the critical mass, the negative impact of non-R\&D shows a significantly increasing tendency. Specifically, neither much higher nor much lower regional innovation level is conducive to the promoting effect of non-R\&D activities. Only when the regions are within the moderate threshold level (critical mass), the negative impact of non-R\&D on innovation performance will decrease to the minimum.

Based on our findings, initial policy conclusions can be drawn. First, when choosing a sustainable innovative mode, China can select the optimal path for non-R\&D depending on the threshold of the innovation level in different regions. The sustainable region innovation level is needed both to stimulate the development of non-R\&D and to make full use of non-R\&D investment to achieve diversified transformation in the innovation sustainability. Only depending on the sustainable innovation foundation to a certain extent, especially the regional innovation level keeping a moderate threshold level, the non-R\&D processes are capable of being digested, absorbed and converted into externally acquired knowledge. That makes acquired knowledge externally becoming the practical resources of enterprises owned, conversely increases the accumulated knowledge of the organization, and reduces the cost and risk of innovation-driven implementation.

Second, we should be alert to the "substitution effect" of non-R\&D activities, which may damage initiatives to engage in innovation sustainability. High technical renovation in non-R\&D innovation activities will prolong the life cycle of existing technologies but also reduce the need for new technology and the inherent power of innovation sustainability, strengthening the "inertia" of innovation sustainability in enterprises. Moreover, non-R\&D activities not only fully meet the technical requirements of enterprises (in most cases), but also have the advantages of a shorter cycle, lower risk and stronger selectivity than internal R\&D. Thus, non-R\&D innovation activities actually serve as a "replacement" for an enterprise's R\&D innovation efforts (substitution effect). This is a matter of great importance to China's innovation. Moreover, China's absorptive capacity should significantly improve innovation performance for non-R\&D activities and open innovation. However, few effective resources are obtained through open innovation: The open mode is singleness, and the breadth and depth of open innovation are generally low and lack the concept of cooperation. Thus, absorptive capacity has no significant effect on innovation. To avoid or reduce the negative effects of these non-R\&D innovation activities, based on enhancing the system of open and multivariate innovation, we should focus both on improving the ability to digest and absorb advanced technology and on enhancing engagement with secondary innovation based 
on "learning by doing." Furthermore, in the long run, with open innovation, China should accurately grasp the transformational trend of innovation sustainability and fully enhance the driving role of non-R\&D modes to achieve the transformation of China's effective innovation sustainability strategy. In practice, for ensuring the sustainable development of innovation economy, we should grasp dynamic capabilities under the complex conditions of highly dynamic changes of social economy in the future, which can be of value in a number of environmental conditions. There is always a need to adapt and improve existing operational capabilities so that they can maintain their value [58]. For example, in the role of Information Technology in driven agility and responsiveness in the global market place, enterprises should focus their IT deployments and the IT-enabled processes to realize sustained competitive performance [59]. Unlike European enterprises, with the deepening of international competition, Chinese enterprises have exposed the disadvantages of their weak innovation ability and serious dependence on foreign technology-i.e., the role of non-R\&D modes is limited, and internal $R \& D$ has long been a national strategy. In contrast, non-R\&D innovation activities with open innovation have long-term significance to Chinese enterprises and national innovation sustainability. R\&D with open innovation does not occur behind closed doors or only involve important technology. However, with the guidance of $R \& D$, companies use the global open market with a variety of modes to seek technical support and resources to achieve the diversification of core technology sources and form their own advanced technology with independent intellectual property rights, continuing to improve the resource situation and regional innovation level through government policies, tax and financial support and other measures and laying a foundation for the scale effects of non-R\&D innovation activities.

Our study has some limitations. The primary limitation is that there may be a threshold effect for other factors beyond the regional innovation level. We welcome future studies that address space and data availability constraints to continue our research by examining other threshold factors that might affect the influence of non-R\&D innovation activities on innovation sustainability. In addition, in future research, it would be better to perform an ecosystem analysis of non-R\&D innovation patterns based on the survey and case study of SMEs for revealing the micro mechanism of non-R\&D innovation's performance in China, providing the convincing basis for the design of variables in the macro-economic study.

Author Contributions: J.H. and J.C. conceived and designed the experiments; J.H. performed the experiments; J.H. and J.C. analyzed the data; H.S. contributed reagents/materials/analysis tools; J.H. and G.W. wrote the paper.

Funding: This research was funded by the Fundamental Research Funds for the Central Universities-grant number [2018RW22].

Acknowledgments: We are indebted to the anonymous reviewers and editor.

Conflicts of Interest: The authors declare no conflict of interest. The founding sponsors had no role in the design of the study; in the collection, analyses, or interpretation of data; in the writing of the manuscript, and in the decision to publish the results.

\section{References}

1. Eccles, R.G.; Serafeim, G. The performance frontier: Innovating for a sustainable strategy. Harv. Bus. Rev. 2013, 91, 17-18.

2. Aguilar-Fernández, M.E.; Otegi-Olaso, J.R. Firm Size and the Business Model for Sustainable Innovation. Sustainability 2018, 10, 4785. [CrossRef]

3. Boons, F.; Lüdeke-Freund, F. Business models for sustainable innovation: State-of-the-art and steps towards a research agenda. J. Clean. Prod. 2013, 45, 9-19. [CrossRef]

4. Hou, J.; Teo, T.S.; Zhou, F.; Lim, M.K.; Chen, H. Does industrial green transformation successfully facilitate a decrease in carbon intensity in China? An environmental regulation perspective. J. Clean. Prod. 2018, 184, 1060-1071. [CrossRef]

5. Chesbrough, H. Open Innovation, the New Imperative for Creating and Profiting from Technology; Harvard Business School Press: Cambridge, MA, USA, 2003. 
6. Santamaría, L.; Nieto, M.J.; Barge-Gil, A. Beyond formal R\&D: Taking advantage of other sources of innovation in low- and medium-technology industries. Res. Policy 2009, 38, 507-517.

7. Sun, Y.; Du, D. Determinants of Industrial innovation in China: Evidence from its recent economic census. Technovation 2010, 30, 540-550. [CrossRef]

8. Cohen, W.M.; Levinthal, D.A. Innovation and learning: The two faces of R\&D. Econ. J. 1989, 99, 569-596.

9. Ebersberger, B.; Lehtoranta, O. Pattern of Innovative Activities among Finnish Firms; VTT: Espoo, Finland, 2005.

10. Ehie, I.C.; Olibe, K. The effect of R\&D investment on firm value: An examination of US manufacturing and service industries. Int. J. Prod. Econ. 2010, 128, 127-135.

11. Garciá-Manjón, J.V.; Romero-Merino, M.E. Research, development, and firm growth. Empirical evidence from European top R\&D spending firms. Res. Policy 2012, 41, 1084-1092.

12. Arundel, A.; Bordoy, C.; Kanerva, M. Neglected Innovators: How do Innovative Firms That Do Not Perform RED Innovate? Results of an Analysis of the Innobarometer 2007 Survey; INNO-Metrics Thematic Paper No. 215; European Commission: Brussels, Belgium, 2008.

13. Wang, Z.; Wang, Y. Evaluation of the provincial competitiveness of the Chinese high-tech industry using an improved TOPSIS method. Expert Syst. Appl. 2014, 41, 2824-2831. [CrossRef]

14. Brouwer, E.; Kleinknecht, A. Measuring the unmeasurable: A country's non-R\&D expenditure on product and service innovation. Res. Policy 1997, 25, 1235-1242.

15. Sterlacchini, A. Do innovative activities matter to small firms in non-R\&D-intensive industries? An application to export performance. Res. Policy 1999, 28, 819-832.

16. OECD. Proposed Standard Practice for Surveys on Research and Experimental Development; Frascati Manual: Paris, France, 2002.

17. Zheng, G.; Liu, F.; Xu, F.; Peng, X.M. Non-R\&D innovation: The neglected side of innovation in SMEs. Sci. Sci. Manag. S. T. 2014, 35, 140-146. (In Chinese)

18. Moilanen, M.; Østbye, S.; Woll, K. Non-R\&D SMEs: External knowledge, absorptive capacity and product innovation. Small Bus. Econ. 2014, 43, 447-462.

19. OECD. Oslo Manual: Guidelines for Collecting and Interpreting Innovation Data; Department of Economic and Community Development Publishing: Paris, France, 2005.

20. OECD. Measuring Innovation: A New Perspective; Department of Economic and Community Development Publishing: Paris, France, 2010.

21. Evangelista, R.; Iammarino, S.; Mastrostefano, V.; Silvani, A. Looking for regional systems of innovation: Evidence from the Italian innovation survey. Reg. Stud. 2002, 36, 173-186. [CrossRef]

22. Evangelista, R.; Mastrostefano, V. Firm size, sectors and countries as sources of variety in innovation. Econ. Innov. New Technol. 2006, 15, 247-270. [CrossRef]

23. Nascia, L.; Perani, G. Diversity of innovation in Europe. Int. Rev. Appl. Econ. 2002, 16, 277-293. [CrossRef]

24. Huang, C.; Arundel, A.; Hollanders, H. How firms innovate: R\&D, non-R\&D and technology adoption'. Presented at the DIME Final Conference, Maastricht, The Netherlands, 6-8 April 2011; pp. 63-69.

25. Kim, L.; Nelson, R.R. Technology, Learning, and Innovation: Experiences of Newly Industrializing Economies; Cambridge University Press: Cambridge, UK, 2000.

26. Heidenreich, M. Innovation patterns and location of European low- and medium-technology industries. Res. Policy 2009, 38, 483-494. [CrossRef]

27. Evangelista, R.; Vezzani, A. The economic impact of technological and organizational innovations. A firm-level analysis. Res. Policy 2010, 39, 1253-1263. [CrossRef]

28. Som, O. Innovation without RED: Heterogeneous Innovation Patterns of Non-RED-Performing Firms in the German Manufacturing Industry; Springer: Berlin, Germany, 2012.

29. Zhou, F.L.; Wang, X.; Lin, Y.; He, Y.D.; Wu, N. Influence research of multi-dimensional tech-innovation behavior on tech-innovation performance. Int. J. Innov. Sci. 2016, 8, 148-160. [CrossRef]

30. Kleinknecht, A.; Reijnen, J.O.N. More evidence on the undercounting of small firm R\&D. Res. Policy 1991, 20, 579-587.

31. Hervas-Oliver, J.; Albors Garrigos, J.; Gil-Pechuan, I. Making sense of innovation by R\&D and non-R\&D innovators in low technology contexts: A forgotten lesson for policymakers. Technovation 2011, 31, 427-446.

32. Hervas-Oliver, J.; Sempere-Ripoll, F.; Boronat-Moll, C.; Rojas, R. Technological innovation without R\&D: Unfolding the extra gains of management innovations on technological performance. Technol. Anal. Strateg. Manag. 2015, 27, 19-38. 
33. Ali-Yrkko, J.; Martikainen, O. The Impact of Technological and Non-Technological Innovations on Firm Growth; Discussion Papers; The Research Institute of the Finnish Economy: Helsinki, Finland, 2008.

34. Lee, Y.; Walsh, J.P. Inventing while you work: Knowledge, non-R\&D learning and innovation. Res. Policy 2016, 45, 345-359.

35. Xie, Z.; Huang, W. Influence of non-R\&D innovation expenditure on innovation performance of high technology industries. Sci. Res. Manag. 2015, 36, 1-10.

36. Chen, Y.F.; Chen, J. A study on the mechanism of open innovation promoting innovative performance. Sci. Res. Manag. 2009, 30,1-9.

37. Guan, J.C.; Chen, K.H. Measuring the innovation production process: A cross-region empirical study of China's high-tech innovations. Technovation 2010, 30, 348-358. [CrossRef]

38. Hansen, B.E. Threshold Effects in Non-Dynamic Panels: Estimation, Testing, and Inference. J. Econ. 1999, 93, 345-368. [CrossRef]

39. Blundell, R.; Bond, S. Initial conditions and moment restrictions in dynamic panel data models. J. Econ. 1998, 87, 115-143. [CrossRef]

40. Agarwal, R.; Sarkar, M.B.; Echambadi, R. The conditioning effect of time on firm survival: An industry lifecycle approach. Acad. Manag. J. 2002, 45, 971-994.

41. Chen, H.; Hou, J.; Chen, W. Threshold Effect of Knowledge Accumulation between Innovation Path and Innovation Performance: New Evidence from China's High-tech Industry. Sci. Technol. Soc. 2018, 23, 163-184. [CrossRef]

42. Kim, B.; Kim, E.; Miller, D.J.; Mahoney, J.T. The impact of the timing of patents on innovation performance. Res. Policy 2016, 45, 914-928. [CrossRef]

43. O’Regan, N.; Kling, G. Technology outsourcing in manufacturing small- and medium-sized firms: Another competitive resource? RED Manag. 2011, 41, 92-105.

44. Rasiah, R.; Shahrivar, R.B.; Yap, X. Institutional support, innovation capabilities and exports: Evidence from the semiconductor industry in Taiwan. Technol. Forecast. Soc. Chang. 2016, 109, 69-75. [CrossRef]

45. Wang, L.; Szirmai, A. Technological inputs and growth in China's high-tech industries. China Econ. Q. 2008, 7, 913-932.

46. Yu, L.P.; Li, S.W.; Liu, J. A comparative study of the impact of technical sources on high-tech industry innovation. Sci. Res. Manag. 2016, 37, 61-67.

47. Gu, Q.; Jiang, W.; Wang, G.G. Effects of external and internal sources on innovation performance in Chinese high-tech SMEs: A resource-based perspective. J. Eng. Technol. Manag. 2016, 40, 76-86. [CrossRef]

48. Wang, C.; Kafouros, M.I. What factors determine innovation performance in emerging economies? Evidence from china. Int. Bus. Rev. 2009, 18, 606-616. [CrossRef]

49. Cao, Y.; Su, F.J. The impact of technological innovation input on innovation performance based on the panel data of Chinese high-tech industries. Sci. Res. Manag. 2012, 33, 22-31.

50. Blomström, M.; Sjöholm, F. Technology transfer and Spillovers: Does Local participation with multinationals matter? Eur. Econ. Rev. 1999, 43, 915-923. [CrossRef]

51. Burhan, M.; Singh, A.K.; Jain, S.K. Patents as proxy for measuring innovations: A case of changing patent filing behavior in Indian public funded research organizations. Technol. Forecast. Soc. Chang. 2017, 123, 181-190. [CrossRef]

52. Furman, J.L.; Porter, M.E.; Stern, S. The determinants of national innovative capacity. Res. Policy 2002, 31, 899-933. [CrossRef]

53. Trajtenberg, M. A penny for your quotes: Patent citations and the value of innovations. Rand J. Econ. 1990, 21, 172-187. [CrossRef]

54. Guan, J.; Chen, K. Modeling the relative efficiency of national innovation systems. Res. Policy 2012, 41, 102-115. [CrossRef]

55. Huang, F.; Rice, J.; Martin, N. Does open innovation apply to China? Exploring the contingent role of external knowledge sources and internal absorptive capacity in Chinese large firms and SMEs. J. Manag. Organ. 2015, 21, 594-613. [CrossRef]

56. Ishikawa, J.; Horiuchi, E. Strategic foreign direct investment in vertically related markets. Econ. Rec. 2012, 88, 229-242. [CrossRef]

57. Gao, L.M.; Ma, W.J. Open innovation: Connotation, framework and Chinese context. Manag. World 2014, 6, 157-169. 
58. Protogerou, A.; Caloghirou, Y.; Lioukas, S. Dynamic capabilities and their indirect impact on firm performance. Ind. Corp. Chang. 2012, 21, 615-647. [CrossRef]

59. Mikalef, P.; Pateli, A. Information technology-enabled dynamic capabilities and their indirect effect on competitive performance: Findings from PLS-SEM and fsQCA. J. Bus. Res. 2017, 70, 1-16. [CrossRef] 